\title{
DIFENZOQUAT FOR WILD OAT CONTROL IN RYEGRASS FOR SEED PRODUCTION
}

\author{
D.J.I. Jacobson
}

ICI Tasman Ltd, Box 7360, Christchurch

\section{SUMMARY}

Difenzoquat has demonstrated a high level of control of wild oat (Avena fatua) at Feekes Growth stages 2-6. Seedlings and young plants of ryegrass (Lolium spp) and white clover (Trifolium repens) were not affected by the difenzoquat treatments.

\section{INTRODUCTION}

Wild oats ( $A$. fatua and occasionally $A$. persica) in ryegrass seed crops are of concern, not only because they may reduce yields (Allen et al 1974), but more importantly because downgrading or rejection of that line can occur if wild oats are found at field inspection; and rejection will occur if they are found in the sample after machine dressing.

TABLE 1: Trial details.

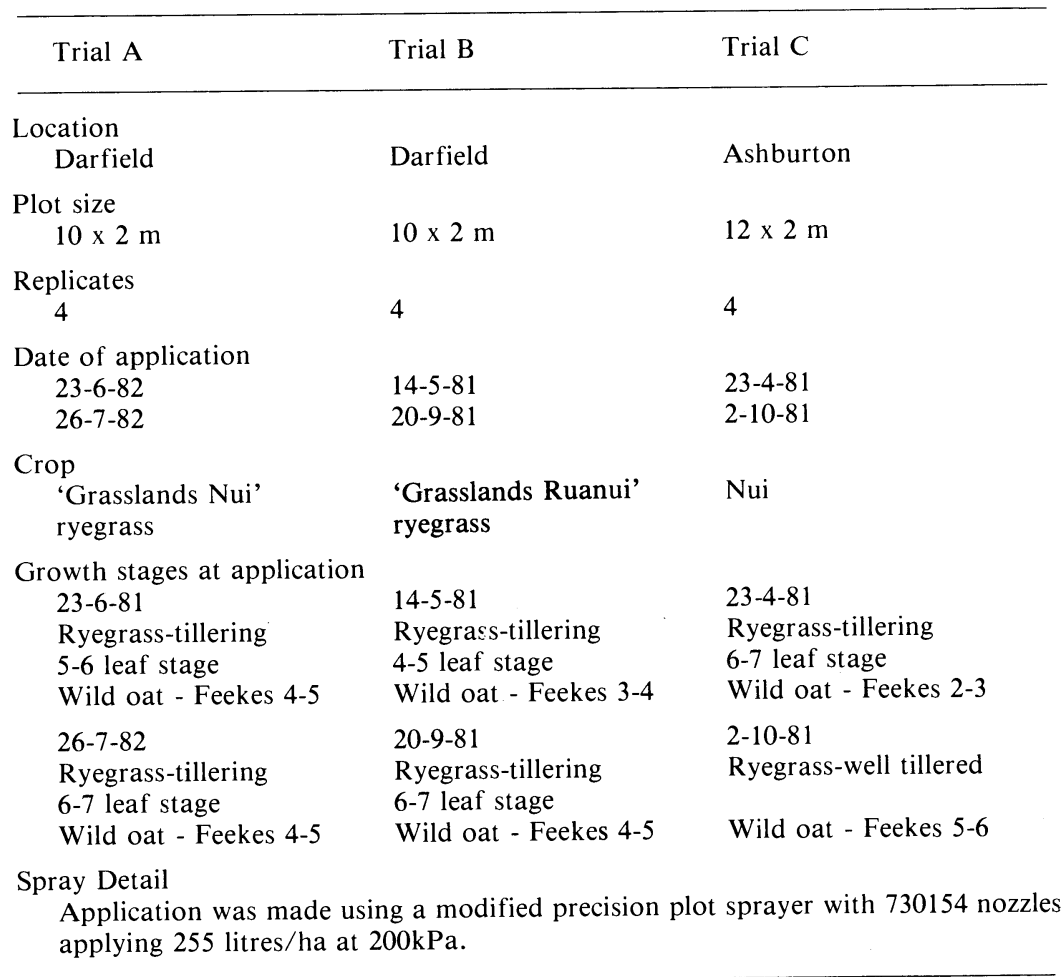

Proc. 36th N.Z. Weed and Pest Control Conf. 
TABLE 2: Chemical treatments, wild oat control and crop yields.

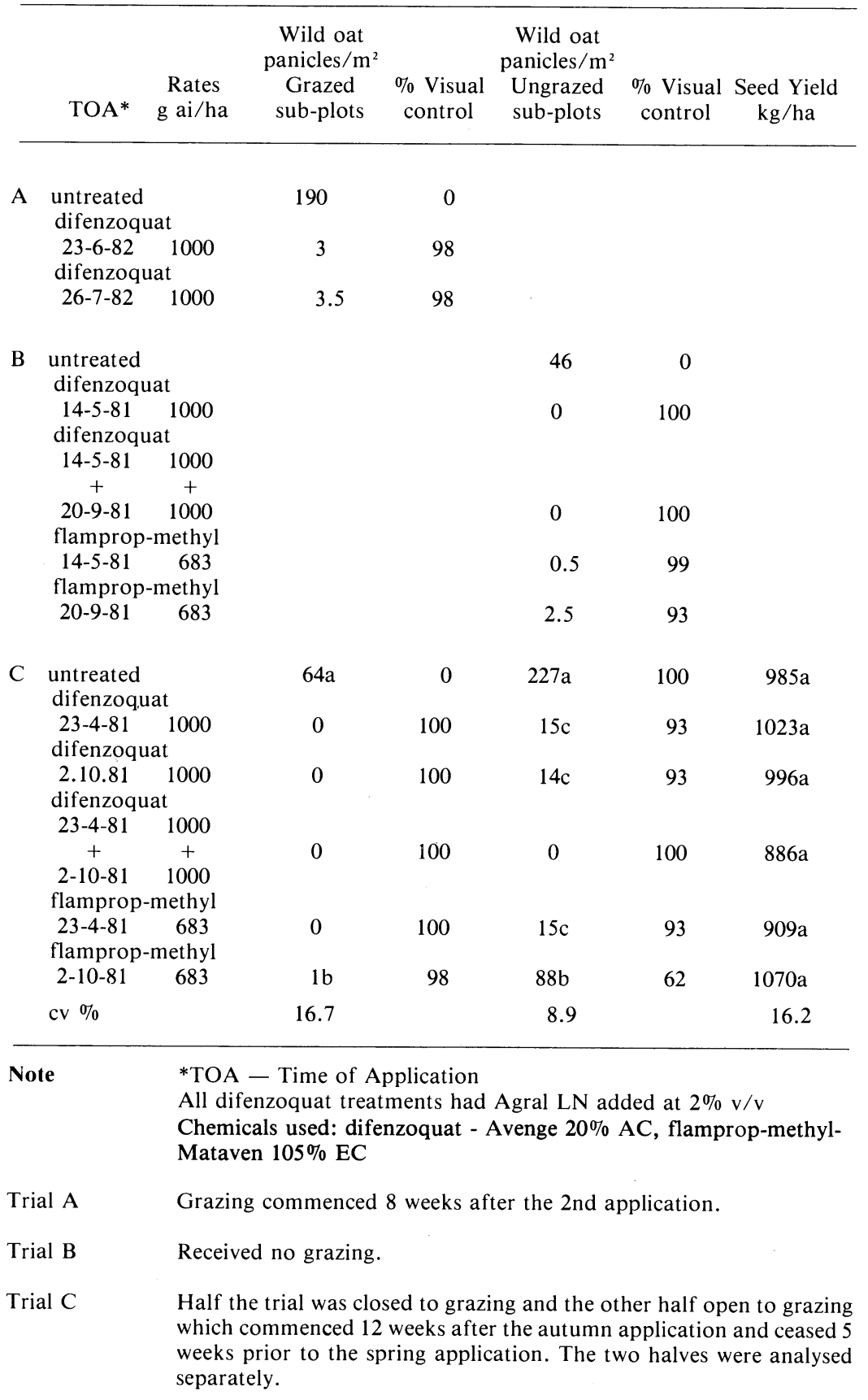




\section{METHOD}

Trial sites were chosen for an even distribution of wild oat, ryegrass and white clover plants. Application details are shown in Table 1. The visual assessments of wild oat control and the wild oat panicle counts shown in Table 2, were undertaken immediately prior to harvest. The grass seed yields on Trial $\mathrm{C}$ were determined by handharvesting $2 \mathrm{~m}^{2}$ from the grazed sub-plots, drying the sample and then threshing on a stationary Kurt Pelz, followed by dressing on a small seed cleaner.

\section{RESULTS AND DISCUSSION}

The results of the three trials are presented in Table 2. They show that difenzoquat, at all times of application, provided a very high level of control of wild oats.

The applications made in the cooler months of June and July in Trial A were slow to effect control of wild oats, and it was not until early spring that collapse and decay of the wild oats were observed.

Both times of application of difenzoquat in Trial B resulted in excellent wild oat control, comparable to that provided by flamprop-methyl from the May application. Difenzoquat was superior to flamprop-methyl at the spring application. The two application regime of difenzoquat in Trial B gave no additional benefit over difenzoquat applied once only, either in the autumn or spring. No germination of wild oats occurred on any trials subsequent to the autumn/early winter applications.

In Trial $\mathrm{C}$ winter grazing following the autumn application of difenzoquat and flamprop-methyl appeared to have a positive effect on the level of wild oat control obtained. Winter grazing prior to the spring application of difenzoquat and flampropmethyl also seemed to have a positive effect on wild oat control. Winter grazing of the untreated plots apparently caused a large mortality of wild oats compared to the ungrazed, untreated plots. On the ungrazed plots difenzoquat applied in the autumn or spring and flamprop-methyl applied in the autumn provided comparable control of wild oats but flamprop-methyl applied in the spring was inferior. The two application regime of difenzoquat provided optimum wild oat control on the ungrazed plots.

No statistical difference exists between treatments on Trial C in terms of grass seed yield. This grass seed crop was very competitive and vigorous, as reflected by the high yields obtained, and was probably able to tolerate the competition from the wild oats. No phytotoxicity to the ryegrass or clover was observed on the trials from any treatment.

\section{CONCLUSIONS}

The results show that difenzoquat has the potential to provide optimum wild oat control in ryegrass seed crops. Ideally, difenzoquat should be applied in the autumn/early winter period when the majority of the wild oats would be at a more susceptible growth stage.

Winter grazing positively influenced the level of wild oat control obtained from both an autumn and a spring application of difenzoquat and flamprop-methyl.

\section{ACKNOWLEDGEMENTS}

The co-operation of the farmers who provided trial sites is gratefully acknowledged.

\section{REFERENCES}

Allen, F.C., Smallridge, T.J., and Bourdot, G.W., 1974. Wild oat control in ryegrass for seed production. Proc. 27th N.Z. Weed and Pest Control Conf.: $67-71$ 